with Rasmussen syndrome. This familial disorder may represent a variant of the classically sporadic and unilateral Rasmussen syndrome. (Silver K, Andermann F, Meagher-Villemure K. Familial alternating epilepsia partialis continua with chronic encephalitis. Another variant of Rasmussen syndrome? Arch Neurol May 1998;55:733-736). (Respond: F. Andermann MD, Montreal Neurological Hospital, 380 University St, Montreal, Quebec, Canada H3A 2B4).

COMMENT. A familial syndrome is described involving two brothers with symptoms and pathology resembling Rasmussen syndrome but with unusual characteristics of bilateral seizure and paresis involvement, early age of onset, and rapid deterioration. A history of parental consanguinity suggests an autosomal recessive inheritance.

\title{
ACADEMIC ACHIEVEMENT IN CHILDREN WITH EPILEPSY
}

Academic achievement, measured by school-administered group tests, child attitudes and self-concept, and teachers rated school adaptive functioning were compared in 117 children with epilepsy and 108 with asthma, ages 8 to 12 years, and data were analyzed at the Indiana University Schools of Nursing, Education, and Medicine, Indianapolis. Children with epilepsy had significantly lower achievement scores, and boys with severe epilepsy were most at risk. Negative attitudes towards the illness and poor self-esteem, and lower school adaptive functioning scores were also related to poor academic achievement. (Austin JK, Huberty TJ, Dunn DW. Academic achievement in children with epilepsy and asthma. Dev Med \& Child Neurol April 1998;40:248-255). (Respond: Joan K Austin, Indiana University School of Nursing, 1111 Middle Drive, NU492, Indianapolis, IN 46202).

COMMENT. Children with epilepsy and especially boys with severe epilepsy are at risk of academic underachievement. Deficiences of neuropsychological function, particularly language skills and attention, have been reported in children with epilepsy. Reduced parental expectations for academic achievement in children with epilepsy lead to impaired school performance. Parent, teacher, and child counseling are essential adjuncts to AED therapy in the management of epilepsy in children. Some local branches of the Epilepsy Foundation of America have volunteer board members who give short talks on epilepsy in grade schools. An increased understanding of epilepsy among school children and peers leads to a heightened self concept of patients.

\section{ANTICONVULSANTS AND LIVER TOXICITY}

\section{LAMOTRIGINE-INDUCED ACUTE HEPATIC FAILURE}

An 8-year-old boy with seizures who developed acute hepatic failure during treatment with lamotrigine is reported from the Department of Pediatrics, Columbia University, New York. The patient was first admitted because of aggressive behavior, ataxia, and tremor caused by valproic acid (VPA) treatment. VPA level was $64 \mathrm{mcg} / \mathrm{ml}$, and blood and liver function tests were normal. Lamotrigine was substituted for the VPA and thioridazine added. Two weeks after discharge, fever, vomiting, headaches and diplopia developed. Thioridazine was discontinued. Three days later, the child entered hospital with jaundice, hepatomegaly, elevated liver enzymes, and coagulopathy. The lamotrigine level was $30 \mathrm{mcg} / \mathrm{ml}(\mathrm{N}, 1-3)$. The drug was discontinued, the boy was treated with iv fluids and vitamin $\mathrm{K} 5 \mathrm{mg}$ im, and he recovered within one week. The hepatic failure was believed to be caused by lamotrigine. (Arnon R, DeVivo D, Defelice AR, 
Kazlow PG. Acute hepatic failure in a child treated with lamotrigine. Pediatr Neurol April 1998;18:251-252). (Respond: Dr Philip G Kazlow, Department of Pediatrics, Columbia University, 630 West 168 th Street, New York, NY 10032).

COMMENT. This appears to be the first case of hepatic failure caused by lamotrigine in a child. The authors cite two previous reports in adults, both after adding lamotrigine to polytherapy, including carbamazepine and/or valproic acid. The previously administered valproic acid in the present case might possibly have contributed to the lamotrigine high blood level and toxicity. Glucuronic acid metabolism is the metabolic pathway of lamotrigine, and valproic acid blocks the elimination of lamotrigine. Careful monitoring of liver function is recommended in patients treated with lamotrigine.

Outcome of children with cerebral edema caused by fulminant hepatic failure is reviewed from the Children's Hospital of Pittsburgh, PA (Alper G, Jarjour IT, Reyes JD et al. Pediatr Neurol April 1998;18:299-304). Neurologic complications of encephalopathy and cerebral edema were major contributors to mortality in $14(70 \%)$ of 20 children with FHF due to various causes. Orthotopic liver transplantation is recommended with severe and worsening encephalopathy before radiographic evidence of cerebral edema develops.

Effect of L-carnitine on valproic acid concentrations in rat serum, brain, and liver was studied at the Department of Pediatrics, Akita University School of Medicine, and Yuri Kumiai General Hospital; Akita, Japan (Sakemi K, Takada G. Pediatr Neurol April 1998;18:331-333). Supplements of carnitine increased free valproic acid concentrations in the brain and may be expected to potentiate the anticonvulsant effects of valproic acid treatment in humans.

\section{HEREDO-DEGENERATIVE DISORDERS}

\section{GENETICS OF CHARCOT-MARIE-TOOTH DISEASE}

The nomenclature, classification, and genetic basis of Charcot-Marie-Tooth (CMT) disease are reviewed from the Department of Molecular and Cell Biology, University of Aberdeen Medical School, Scotland. Electrophysiological examination with nerve conduction studies and nerve pathology allow subdivision of CMT disease into two major types, CMT type 1 and type 2. CMT 1, also called hereditary motor and sensory neuropathy (HMSNI) is most common and is characterized by slow nerve conduction velocities (NCV), and "onion bulbs" in nerve biopsy due to demyelination and remyelination. CMT2 (HMSNII) has normal NCVs and myelination but marked axonal degeneration. CMT is both clinically and genetically heterogeneous. The duplication of a $1.5 \mathrm{Mb}$ DNA fragment on the PMP22 gene of chromosome $17 \mathrm{p} 11.2$ is associated with more than $70 \%$ of CMT1 cases. Point mutations of the PMP22 gene are also associated with CMT 1 phenotype. PMP22 duplication testing is the initial screen in CMT disease diagnosis, accounting for $70 \%$ of CMT1 cases. Cx32 screening will uncover the second most common genetic defect. (Bell C, Haites N. Genetic aspects of CharcotMarie-Tooth disease. Arch Dis Child April 1998;78:296-300). (Respond: Drs Bell and Haites, Medical Genetics, University of Aberdeen Medical School, Foresterhill, Aberdeen AB25 2ZD, Scotland). 